\title{
Evaluation and Examination of Aperture Oriented Antennas
}

\author{
Prof. Romi Morzelona \\ Professor, Department of Computer Science, Russia \\ romimorzelona@mail.ru
}

\begin{tabular}{|c|c|}
\hline Article History & Abstract \\
\hline $\begin{array}{l}\text { Article Submission } \\
19 \text { November } 2016 \\
\text { Revised Submission } \\
17 \text { January } 2017 \\
\text { Article Accepted } \\
1 \text { March } 2017 \\
\text { Article Published } \\
31^{\text {st }} \text { March } 2017\end{array}$ & $\begin{array}{l}\text { The exhaustive evaluation and analysis of aperture oriented antennas for different } \\
\text { dimensions at two different frequencies (1800 MHz and } 2.4 \mathrm{GHz}) \text { is presented in this } \\
\text { paper. Design and comparison of the antennas for their performance is done through } \\
\text { MATLAB. It is inferred that the circular aperture antenna has } 95 \% \text { higher directivity } \\
\text { than rectangular aperture antenna. In addition, for the circular aperture antenna } \\
H P B W \text { is } 0.2849 \text { degrees and for rectangular aperture } H P B W \text { is } 1.0143 \text { degrees. } \\
\text { Also, circular patch antenna has less side lobe power than that of rectangular } \\
\text { aperture antenna. } \\
\text { Keywords: aperture antenna, electromagnetic radiation, directivity, beam width. }\end{array}$ \\
\hline
\end{tabular}

\section{Introduction}

An antenna that has a part of its structure as physical aperture through which electromagnetic wave flow is known as an aperture antenna and it is most widely used in microwave frequencies. Aperture antennas are used in the applications requiring high directivity. Aperture antennas have two common shapes, one is rectangular and another circular [1][2]. Aperture antenna with rectangular and circular shapes is selected to evaluate the radiation pattern, directivity and beam width in this paper. The uniform distribution is considered to demonstrate the electromagnetic field distribution [3][4]. This paper is proposed to analyze the performance of the rectangular and circular aperture antenna with respect to directivity and beam width for different dimensions and for two different frequencies $(2.4 \mathrm{GHz}$ and $1800 \mathrm{MHz})$.

The aperture based rectangular antenna is the most wanted microwave based antenna as it follows rectangular co-ordination module. The module efficiently express the field and performs easier integration [5].

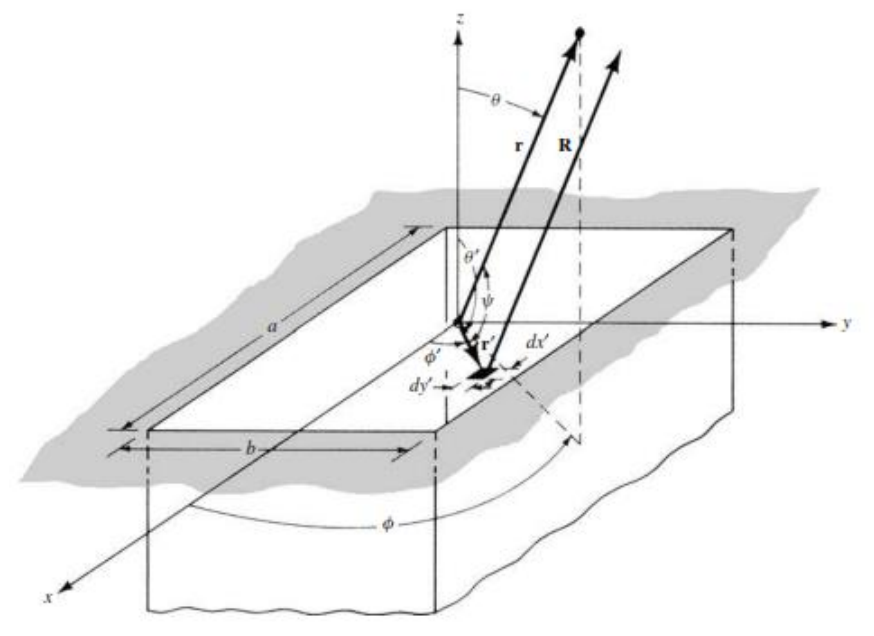

Fig 1: Aperture based Rectangular antenna on ground plane 
Let us assume the rectangular aperture is placed in the xy plane of the infinite ground plane.

The differential path takes the form of

$$
\begin{aligned}
r^{\prime} \cos \psi & =r^{\prime} \cdot \widehat{a_{r}}=\left(\widehat{a_{x}} \cdot x^{\prime}+\widehat{a_{y}} \cdot y^{\prime}\right) \cdot\left(\widehat{a_{x}} \cdot \sin \theta \cos \emptyset+\widehat{a_{y}} \cdot \sin \theta \sin \emptyset+\widehat{a_{z}} \cdot \cos \theta\right) \\
& =x^{\prime} \sin \theta \cos \emptyset+y^{\prime} \sin \theta \sin \emptyset
\end{aligned}
$$

Far-zone field radiation by aperture antenna is given as

$$
\begin{aligned}
E_{r} & =0 \\
E_{\theta} & =j \frac{a b k E_{0} e^{-j k r}}{2 \pi r}\left[\sin \emptyset\left(\frac{\sin X}{X}\right)\left(\frac{\sin Y}{Y}\right)\right] \\
E_{\varnothing} & =j \frac{a b k E_{0} e^{-j k r}}{2 \pi r}\left[\cos \theta \cos \emptyset\left(\frac{\sin X}{X}\right)\left(\frac{\sin Y}{Y}\right)\right] \\
H_{r} & =0 \\
H_{\theta} & =-\frac{E_{\emptyset}}{\eta} \\
H_{\varnothing} & =\frac{E_{\theta}}{\eta}
\end{aligned}
$$

The 2-Dimension plot is sufficient to represent the radiation fields. Below equations describe the E-plane and H-plane

$$
\begin{aligned}
E_{r} & =E_{\varnothing}=0 \\
E_{\theta} & =j \frac{a b k E_{0} e^{-j k r}}{2 \pi r}\left[\frac{\sin \left(\frac{k b}{2} \sin \theta\right)}{\frac{k b}{2} \sin \theta}\right] \\
E_{r} & =E_{\theta}=0 \\
E_{\varnothing} & =j \frac{a b k E_{0} e^{-j k r}}{2 \pi r}\left\{\cos \theta\left[\frac{\sin \left(\frac{k a}{2} \sin \theta\right)}{\frac{k a}{2} \sin \theta}\right]\right\}
\end{aligned}
$$

If the aperture antenna dimensions is greater than the wavelength, then the multiple side lobes appears in the radiation pattern. The number of side lobes increases as the dimension increases [6].

\section{Analysis of rectangular and circular aperture antennas}

In aperture based circular antennas, cylindrical coordinates is followed for the solution of the fields. The differential paths and differential areas can be written as

$r^{\prime} \cos \psi=x^{\prime} \sin \theta \cos \emptyset+y^{\prime} \sin \theta \sin \emptyset=\rho^{\prime} \sin \theta \cos \left(\varnothing-\emptyset^{\prime}\right)$

$d s^{\prime}=d x^{\prime} d y^{\prime}=\rho^{\prime} d \rho^{\prime} d \emptyset^{\prime}$

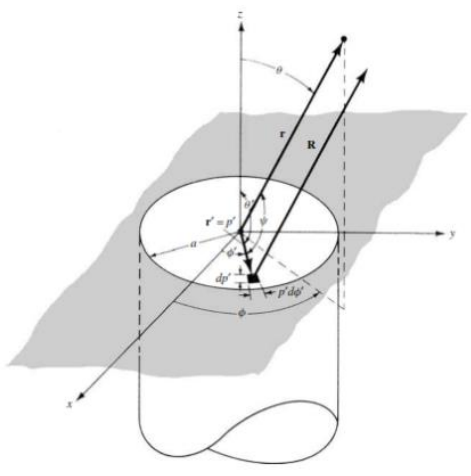

Fig 2: Circular aperture antenna on infinite ground plane. 
Circular aperture mounted on an infinite ground based plane, and the field is over the opening is assumed to be constant [9][10] and is

$$
E_{a}=\hat{a}_{y} E_{0} \quad \rho^{\prime} \leq a
$$

Where $\mathrm{E}_{0}$ is a constant.

$$
\begin{array}{lr}
M_{s}=\left\{\begin{array}{lr}
-2 \hat{n} \times E_{a}=+\hat{a}_{x} 2 E_{0}, & \begin{array}{r}
\rho^{\prime} \leq a \\
0,
\end{array} \\
\text { elsewhere }
\end{array}\right. \\
J_{s}=0 & \text { everywhere }
\end{array}
$$

Electric field components in $\mathrm{E}$ and $\mathrm{H}$ plane can be simplified as

E-Plane $(\varnothing=\pi / 2)$

$$
\begin{gathered}
E_{r}=E_{\emptyset}=0 \\
E_{\theta}=j \frac{k a^{2} E_{0} e^{-j k r}}{r}\left[\frac{\mathrm{J}_{1}(k a \sin \theta)}{k a \sin \theta}\right]
\end{gathered}
$$

H-Plane $(\varnothing=0)$

$$
\begin{gathered}
E_{r}=E_{\theta}=0 \\
E_{\varnothing}=j \frac{k a^{2} E_{0} e^{-j k r}}{r}\left\{\cos \theta\left[\frac{\mathrm{J}_{1}(k a \sin \theta)}{k a \sin \theta}\right]\right\}
\end{gathered}
$$

The directivity for the aperture antenna can be found by computing the radiated power $\left(\mathrm{P}_{\mathrm{rad}}\right)$ and the maximum radiation intensity $\left(U_{\max }\right)$.As the aperture is on infinite based ground of plane, radiated power is high. The average PDF is calculated for the fields at physical bounds of the aperture [7][8].

\section{ANALYSIS AND SIMULATION RESULTS}

The maximum radiation intensity occurs at $\theta=00$. The beam width is termed as the angle of separation between two points on max. Pattern HPBW is defined as the degree of radiation intensity maximum occurring at one-half beam value. Another important terminology is First Null Beam width (FNBW) which is the angular separation occurring between the first nulls of the pattern.

Thus the total HPBW of the rectangular aperture antenna is given by

$$
\Theta_{h}=2 \theta_{h}=2 \sin ^{-1}\left(\frac{0.443 \lambda}{b}\right) \mathrm{rad}=114.6 \sin ^{-1}\left(\frac{0.443 \lambda}{b}\right) \text { degrees }
$$

When $\mathrm{b}>>0.443 \lambda$ then

$$
\Theta_{h} \cong\left(0.886 \frac{\lambda}{b}\right) \mathrm{rad}=50.8\left(\frac{\lambda}{b}\right) \text { degrees }
$$


The rectangular aperture antenna parameters at the frequency of $1800 \mathrm{MHz}$ are given in Table 1 .

TABLE 1: rectangular aperture antenna parameters at the frequency of $1800 \mathrm{MHz}$

\begin{tabular}{|l|l|l|l|l|l|}
\hline A (cm) & B(cm) & Area (cm2) & Directivity & $\begin{array}{l}\text { HPBW } \\
\text { E plane } \\
\text { (degree) }\end{array}$ & $\begin{array}{l}\text { FNBW E plane } \\
\text { (degree) }\end{array}$ \\
\hline 2.286 & 1.016 & 2.322 & $1.05 \mathrm{E}+03$ & 8.3005 & 18.799 \\
\hline 2.323 & 1.345 & 3.124 & $1.41 \mathrm{E}+03$ & 6.2701 & 14.2007 \\
\hline 3.333 & 1.032 & 3.439 & $1.56 \mathrm{E}+03$ & 8.1718 & 18.5078 \\
\hline 3.000 & 1.613 & 4.839 & $2.19 \mathrm{E}+03$ & 5.2284 & 11.8413 \\
\hline 4.130 & 2.286 & 9.441 & $4.27 \mathrm{E}+03$ & 3.6891 & 8.3552 \\
\hline 4.286 & 2.323 & 9.956 & $4.50 \mathrm{E}+03$ & 3.6304 & 8.2221 \\
\hline 5.229 & 3.456 & 18.071 & $8.18 \mathrm{E}+03$ & 2.4402 & 5.5266 \\
\hline 5.489 & 3.986 & 21.879 & $9.90 \mathrm{E}+03$ & 2.1157 & 4.7918 \\
\hline 6.453 & 3.689 & 23.805 & $1.08 \mathrm{E}+04$ & 2.2861 & 5.1776 \\
\hline 6.236 & 4.101 & 25.623 & $1.16 \mathrm{E}+04$ & 2.0564 & 4.6574 \\
\hline
\end{tabular}

The rectangular aperture antenna parameters at the frequency of $1800 \mathrm{MHz}$ are given in Table 2 .

TABLE 2: rectangular aperture antenna parameters at the frequency of $2.4 \mathrm{GHz}$

\begin{tabular}{|l|l|l|l|l|l|}
\hline $\mathbf{A}(\mathbf{c m})$ & $\mathbf{B}(\mathbf{c m})$ & Area $(\mathbf{c m} 2)$ & Directivity & $\begin{array}{l}\text { HPBW } \\
\text { E plane } \\
\text { (degree) }\end{array}$ & $\begin{array}{l}\text { FNBW E plane } \\
\text { (degree) }\end{array}$ \\
\hline 2.286 & 1.016 & 2.322 & $1.05 \mathrm{E}+03$ & 6.2254 & 14.0994 \\
\hline 2.323 & 1.345 & 3.124 & $1.41 \mathrm{E}+03$ & 4.7026 & 10.6506 \\
\hline 3.333 & 1.032 & 3.439 & $1.56 \mathrm{E}+03$ & 6.1289 & 13.8808 \\
\hline 3.000 & 1.613 & 4.839 & $2.19 \mathrm{E}+03$ & 3.9213 & 8.8810 \\
\hline 4.130 & 2.286 & 9.441 & $4.27 \mathrm{E}+03$ & 2.7668 & 6.2664 \\
\hline 4.286 & 2.323 & 9.956 & $4.50 \mathrm{E}+03$ & 2.7228 & 6.1666 \\
\hline 5.229 & 3.456 & 18.071 & $8.18 \mathrm{E}+03$ & 1.8302 & 4.1450 \\
\hline 5.489 & 3.986 & 21.879 & $9.90 \mathrm{E}+03$ & 1.5868 & 3.5938 \\
\hline 6.453 & 3.689 & 23.805 & $1.08 \mathrm{E}+04$ & 1.7146 & 3.8832 \\
\hline 6.236 & 4.101 & 25.623 & $1.16 \mathrm{E}+04$ & 1.5423 & 1.0143 \\
\hline
\end{tabular}

The circular aperture antenna parameters at the frequency of $1800 \mathrm{MHz}$ are given in Table 3 .

TABLE 3: Circular aperture antenna parameters at the frequency of $1800 \mathrm{MHz}$

\begin{tabular}{|l|l|l|l|l|}
\hline $\mathbf{a}(\mathbf{c m})$ & Area (cm2) & Directivity & $\begin{array}{l}\text { HPBW } \\
\text { E plane } \\
\text { (degree) }\end{array}$ & $\begin{array}{l}\text { FNBW E plane } \\
\text { (degree) }\end{array}$ \\
\hline 1.161 & 2.322 & $1.92 \mathrm{E}+03$ & 4.1918 & 10.0345 \\
\hline 1.562 & 3.124 & $3.47 \mathrm{E}+03$ & 3.1157 & 7.4584 \\
\hline 1.719 & 3.439 & $4.20 \mathrm{E}+03$ & 2.8311 & 6.7772 \\
\hline 2.419 & 4.839 & $8.32 \mathrm{E}+03$ & 2.0119 & 4.8160 \\
\hline 4.720 & 9.441 & $3.17 \mathrm{E}+04$ & 1.0311 & 2.4682 \\
\hline
\end{tabular}




\begin{tabular}{|l|l|l|l|l|}
\hline 4.978 & 9.956 & $3.52 \mathrm{E}+04$ & 0.9776 & 2.3403 \\
\hline 9.035 & 18.071 & $1.16 \mathrm{E}+05$ & 0.5386 & 1.2894 \\
\hline 10.939 & 21.879 & $1.70 \mathrm{E}+05$ & 0.4449 & 1.0650 \\
\hline 11.902 & 23.805 & $2.01 \mathrm{E}+05$ & 0.4089 & 0.9788 \\
\hline 12.811 & 25.623 & $2.33 \mathrm{E}+05$ & 0.3799 & 0.9094 \\
\hline
\end{tabular}

The circular aperture antenna parameters at the frequency of $2.4 \mathrm{GHz}$ are given in Table 4.

TABLE 4: Circular aperture antenna parameters at the frequency of $2.4 \mathrm{GHz}$

\begin{tabular}{|l|l|l|l|l|}
\hline $\mathbf{a}(\mathbf{c m})$ & Area (cm2) & Directivity & $\begin{array}{l}\text { HPBW } \\
\text { E plane } \\
\text { (degree) }\end{array}$ & $\begin{array}{l}\text { FNBW E plane } \\
\text { (degree) }\end{array}$ \\
\hline 1.161 & 2.322 & $3.41 \mathrm{E}+03$ & 3.1438 & 7.5258 \\
\hline 1.562 & 3.124 & $6.16 \mathrm{E}+03$ & 2.3367 & 5.5938 \\
\hline 1.719 & 3.439 & $7.47 \mathrm{E}+03$ & 2.1233 & 5.0829 \\
\hline 2.419 & 4.839 & $1.48 \mathrm{E}+04$ & 1.5089 & 3.6120 \\
\hline 4.72 & 9.441 & $5.63 \mathrm{E}+04$ & 0.7733 & 1.8512 \\
\hline 4.978 & 9.956 & $6.26 \mathrm{E}+04$ & 0.7332 & 1.7552 \\
\hline 9.035 & 18.071 & $2.06 \mathrm{E}+05$ & 0.404 & 0.9671 \\
\hline 10.939 & 21.879 & $3.02 \mathrm{E}+05$ & 0.3337 & 0.7987 \\
\hline 11.902 & 23.805 & $3.58 \mathrm{E}+05$ & 0.3067 & 0.7341 \\
\hline 12.811 & 25.623 & $4.15 \mathrm{E}+05$ & 0.2849 & 0.6820 \\
\hline
\end{tabular}

On the basis of the present work, directivity and HPBW are evaluated for both rectangular and circular aperture. In perspective of directivity, the circular aperture antenna shows superiority over the rectangular aperture for the same aperture dimensions. As directivity increases, First Null Beam width (FNBW) starts decreasing. In addition, Radiation pattern of aperture antenna shows that number of side lobes increased with increase in directivity.

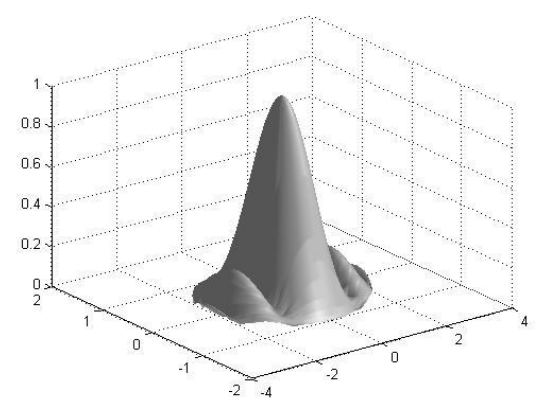

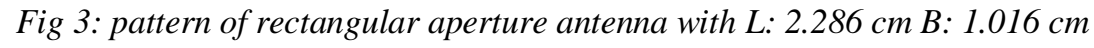

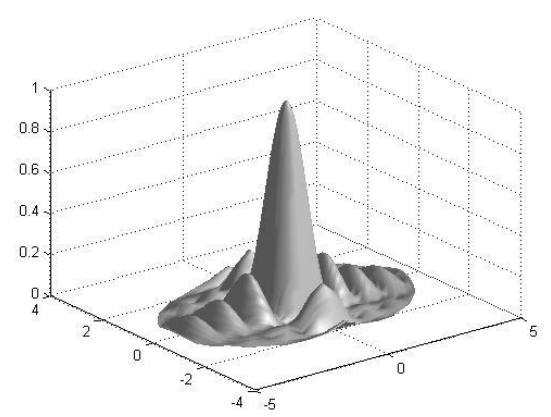

Fig 4: pattern of rectangular aperture antenna with L: $4.286 \mathrm{~cm} \mathrm{B:} 2.323 \mathrm{~cm}$. 


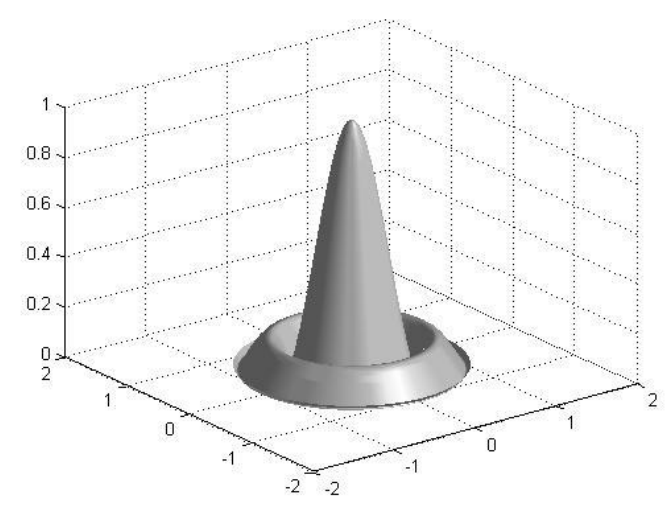

Fig 5: pattern of circular aperture antenna with dimension of Radius: $1.161 \mathrm{~cm}$.

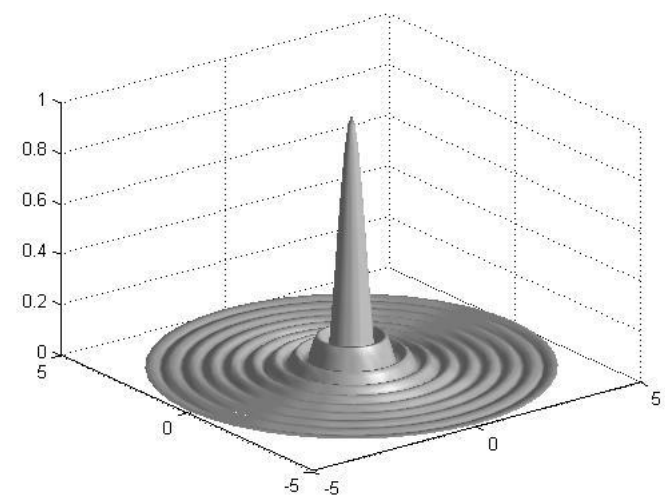

Fig 6: pattern of circular aperture antenna with dimension of Radius: $1.161 \mathrm{~cm}$.

\section{Conclusion}

Comparison between rectangular and circular aperture antenna has been simulated and results are obtained using MATLAB. In both aperture antennas, directivity increases with dimensions of the aperture. However, half power beam width decreases. Circular aperture antenna has high directivity of $4.1467 \mathrm{e}+005$ at aperture area of 25.623 square.cm. Directivity of the circular aperture antenna has $95 \%$ improved directivity when compared to rectangular aperture antenna (Directivity $=2.06 \mathrm{E}+04$ at aperture area of 25.623 square. $\mathrm{cm}$ ) and hence it can be used in applications of Satellite Communication, Radar Engineering.

\section{References}

[1] Constantine A. Balanis "Antenna Theory - Analysis and Design" in Wiley India Edition.

[2] W. L. Stutzman and G. A. Thiele,Antenna Theory and Design,Wiley, New York, 1998.

[3] R. F. Harrington,Time-Harmonic Electromagnetic Fields, McGraw-Hill, New York, 1962, pp. 100-103, 143-263, 365-367.

[4] K. Wincza, S. Gruszczynski, A. Rydosz and I. Slomian, "Octave-band aperture-stakced microstrip antenna element for wideband antenna arrays," 2016 IEEE International Symposium on Antennas and Propagation (APSURSI), Fajardo, 2016, pp. 1579-1580, doi: 10.1109/APS.2016.7696496.

[5] Sophocles J. Orfanidis, Electromagnetic waves and Antennas Theory and Design, Rutgers University.

[6] R. S. Elliott, Antenna Theory and Design, 1st ed., Prentice-Hall, 594 p., 1981. Revised ed., WileyIEEE Press, 594 p., 2003.

[7] W. Obaid, A. Hamid and M. A. Samad, "Multi-frequency CPW bow-tie aperture antenna with rectangular and U shape metal strips," 2016 5th International Conference on Electronic Devices, 
Systems and Applications (ICEDSA), Ras Al Khaimah, 2016, pp. 1-4, doi: 10.1109/ICEDSA.2016.7818464.

[8] A. Bhutani et al., "122 GHz aperture-coupled stacked patch microstrip antenna in LTCC technology," 2016 10th European Conference on Antennas and Propagation (EuCAP), Davos, 2016, pp. 1-5, doi: 10.1109/EuCAP.2016.7481147.

[9] P. R. Akbar, H. Saito, M. Zang, J. Hirokawa and M. Ando, "X-band parallel-plate slot array antenna for SAR sensor onboard $100 \mathrm{~kg}$ small satellite," 2015 IEEE International Symposium on Antennas and Propagation \& USNC/URSI National Radio Science Meeting, Vancouver, BC, 2015, pp. 208-209, doi: 10.1109/APS.2015.7304490.

[10] R. Gupta and R. Yaduvanshi, "Reconfigurable aperture coupled rectangular dielectric resonator antenna," 2015 2nd International Conference on Computing for Sustainable Global Development (INDIACom), New Delhi, 2015, pp. 859-862.

[11] Ms. Madhuri Zambre. (2012). Performance Analysis of Positive Lift LUO Converter . International Journal of New Practices in Management and Engineering, 1(01), 09 - 14. Retrieved from http://ijnpme.org/index.php/IJNPME/article/view/3

[12] Mr. Dharmesh Dhabliya. (2012). Intelligent Banal type INS based Wassily chair (INSW). International Journal of New Practices in Management and Engineering, 1(01), 01 - 08. 